Cuadernos de Trabajo Social

ISSN: 0214-0314

\title{
Privadas de lo público: la ciudadanía a tiempo parcial
}

El Sistema de Bienestar en nuestro país trajo consigo un cierto grado de consenso en cuanto a los medios necesarios para combatir la desigualdad, como garantizar el acceso a la alimentación, la sanidad y la educación o la vivienda. Durante los últimos 30 años, los Servicios Sociales y el tercer sector han trabajado de la mano para consolidar estos derechos, apoyados por políticas que, en mayor o menor medida, se alejaban paulatinamente de la caridad, caminando hacia estructuras basadas en la Justicia Social.

En un momento como este, tan marcado por la incertidumbre, pienso que nuestra labor profesional como trabajadores y trabajadoras sociales, pasa más por hacernos preguntas que por precipitar repuestas y transformarlas en decisiones poco ponderadas, especialmente porque estas repercuten de forma decisiva en la vida de los demás. Por este motivo, no pretendo escribir un artículo con la intención de sentar cátedra, sino compartir una serie de preguntas que alimenten un proceso de reflexión colectiva sobre los derechos y deberes de ciudadanía.

\section{¿Cómo lograr unos ingresos garantizados?}

En la medida en que vamos tomando conciencia de que los cambios en el mercado laboral hacen inviable la idea del pleno empleo y vamos a atender cada vez a más personas en situación vulnerable, se abre de nuevo el debate sobre la necesidad de ofrecer una alternativa al trabajo remunerado como garantía de acceso a unos ingresos mínimos. Al calor de este diálogo, el Ingreso Mínimo Vital (IMV) se posicionaba como una propuesta a medio camino entre la Renta Mínima de Inserción (en sus diversas versiones autonómicas) y la Renta Básica Universal. Sin embargo, ni su ejecución está logrando llegar a todas las personas que la necesitan, ni su filosofía antepone el derecho a la condicionalidad.

El exceso de burocracia, la exclusión de personas que no tienen permiso legal de residencia, la falta de claridad de los reglamentos, los problemas relacionados con la conformación de las unidades de convivencia y/o el empadronamiento, la brecha digital, el desconocimiento del idioma, la falta de atención presencial, etc., son muchas las barreras que excluyen del acceso al sistema de prestaciones a las personas que los necesitan, tantas como los frentes en los que podemos trabajar para garantizar el acceso a estos derechos.

\section{¿Atienden los proyectos a todas las necesidades de sus participantes?}

Además de las carencias del sistema de prestaciones públicas, también en los proyectos que ejecuta el Tercer Sector, encontramos dificultades relacionadas con el planteamiento de los mismos desde la administración. En las bases reguladoras de las subvenciones que financian este tipo de proyectos hay un excesivo protagonismo de criterios meramente cuantitativos (inserciones laborales, gasto por participante, número de personas atendidas). Dicha evaluación sesga los resultados del trabajo que se realiza con estas personas. Más allá de la necesidad de alimentos, el aseo personal o la búsqueda de empleo, las personas que atendemos necesitan un apoyo a largo plazo en su proceso de inclusión, un grupo de referencia, un espacio de socialización en términos de igualdad. A diferencia del rápido desarrollo de los procesos de exclusión, los procesos de inclusión son mucho más lentos, y nos encontramos con personas que necesitarán un cierto grado de supervisión durante toda su vida. 


\section{¿Existe solución al problema habitacional?}

Disponer de un espacio privado, cada vez es más complicado por el elevado precio de las habitaciones y pisos, la gran cantidad de requisitos para acceder a un alquiler, los prejuicios existentes hacia determinados colectivos (migrantes, beneficiarios de los servicios sociales, etc.). Las personas en situación de pobreza no suelen acceder ni siquiera a una vivienda compartida, sino que tienen que destinar la mayoría de sus ingresos a alquilar un cuarto, generalmente sin un contrato ni la posibilidad de empadronarse en casa de personas desconocidas, con las que no existen espacios de convivencia en términos de igualdad, aislados en habitaciones, sin cocina, sin poder acceder al salón para relacionarse y sin posibilidad de reunirse con otras personas.

Fuera del horario en que las personas participantes asisten a proyectos como el nuestro (centro de día), se abre el abismo del aislamiento, una tarde por delante sin nada que hacer, un fin de semana encerrados en 10 metros cuadrados. La pandemia ha funcionado como un laboratorio distópico para la mayor parte de la sociedad, haciendo que las consecuencias de este aislamiento no nos sean tan ajenas ahora que hemos tenido que sufrirlas circunscritos a una casa. Sin embargo, desconocemos lo que es hacerlo en una sola habitación de forma permanente.

\section{¿Las personas pobres se acomodan a su situación?}

Otra de las amenazas de nuestro Sistema de Bienestar es como la polarización política se traslada a las relaciones ciudadanas. Asistimos con preocupación al avance de discursos aporofóbicos. Se extiende, incluso entre la clase trabajadora, el discurso de que las prestaciones/ayudas económicas son un lujo que no están dispuestos a sufragar con sus impuestos, que las personas que "no hacen nada" se acomodan a vivir de las ayudas sin dar palo al agua. Hablamos de personas cuyo proyecto de vida -en términos económicos- llega apenas a la mitad del salario mínimo.

Este clima de confrontación entre los sectores más bajos de la sociedad, cuya dinámica de odio se traslada de arriba hacia abajo, es la muestra de la profunda perversión de una so- ciedad despojada de moral que navega al más puro estilo neoliberal.

Es el triunfo del individualismo, la consideración de la solidaridad como debilidad, de la desigualdad como un problema que incumbe únicamente a los que la padecen y no al conjunto de la sociedad, la pobreza entendida como una decisión, y no como la consecuencia de un conjunto de factores que van más allá de la responsabilidad única de quienes la padecen. Todos estos factores nos llevan a rechazar a las personas pobres, en vez de luchar contra las situaciones de pobreza.

\section{¿Existen limitaciones de acceso al espacio público?}

Paradójicamente, el espacio público, tradicional punto de encuentro y socialización desde tiempos del ágora griega, se ha convertido para las personas en situación de exclusión social en lugar de aislamiento, en vez de espacio de socialización. Es más, se criminalizan ciertos comportamientos sobre el uso de la calle, juzgándolos desde una moral clasista basada en la posición económica (criminalización de clase). Por ejemplo -y de forma especialmente marcada en este mundo pandémico- se persiguen las reuniones en los parques, mientras que permite un ejercicio de irresponsabilidad controlada en bares y terrazas. Una doble moral que no castiga el hecho (beber alcohol), sino a quién lo ejecuta.

La posición económica limita el acceso al sistema de transportes, la oferta cultural, deportiva y de ocio en general. Sin embargo, hay ocasiones en que lo que más determina las situaciones de exclusión no es la propia pobreza, sino nuestra mirada sobre ella.

\section{¿Qué hemos aprendido de la pandemia?}

Durante la pandemia, en mi experiencia, trabajando con personas en grave exclusión social, he observado un dato bastante revelador y sintomático: el número de infectados por la COVID-19, en el colectivo de personas sin hogar, ha sido bastante escaso. Una explicación podemos encontrarla en su imposibilidad de acceder al espacio público (restaurantes, teatros, bares, museos), otra en el reducido número de personas con las que se relacionan, conformando grupos burbuja naturales. Frente 
a esta realidad, contrasta otra: han sido varios los casos de brotes en macro-recursos de alojamiento (albergues) que no permiten ni disfrutar de unos mínimos de privacidad, ni de unas condiciones que garanticen la distancia social ni minimicen el riesgo de contagio.

Necesitamos dar soluciones habitacionales estables, más allá de la emergencia sanitaria, más allá de la emergencia social.

\section{¿Somos realmente todas las personas ciudadanas de pleno derecho?}

Además de la económica, hay multitud de barreras que dificultan la convivencia: culturales, documentales, idiomáticas, de acceso a las nuevas tecnologías, etc.; asistimos a un proceso de segregación que, paradójicamente, se ve alimentado por la homogeneidad de los grupos, dando como resultado un creciente desconocimiento de las personas de fuera de nuestro círculo y la agudización de los prejuicios hacia ellas.

Si entendemos la libertad de los otros como una amenaza, dejar de considerarlos como semejantes se convierte en una maquiavélica, pero útil, herramienta. De esta forma, las personas pobres dejan de ser sujetos y pasan a ser objetos.

Sin tener delante a un igual, a un sujeto, es más fácil negarle la posibilidad de hacerlo bien (o mal) y presuponer que lo que quiere es engañarnos, arrebatarnos lo poco que nos eleva por encima de él. De esta forma, el enemigo no es quien produce la desigualdad, sino los que la padecen.

Todos tenemos el derecho y el deber de dotar de identidad a nuestra sociedad, pero cuando hablamos de la falta de participación de las personas vulnerables, no tenemos que juzgar únicamente su falta de voluntad, también hay que tener en cuenta como nuestra mirada peyorativa sobre las personas en situación de exclusión ha ido calando en su propio autoconcepto.

\section{¿Qué solución existe ante este problema?}

Bajo mi punto de vista, las rentas condicionadas crean ciudadanos dependientes. La ciudadanía (y los principios que la conforman) no puede estar supeditada a nada. Solo lo incondicional crea un derecho y una responsabilidad social compartida.

Si hay una salida a las situaciones de exclusión, esa es la participación. Como dice Pedro Cabrera:

Aunque pudiera parecer que lo opuesto a exclusión es la inclusión (...) hay un antónimo que lo define mejor, que es el de participación. Poder participar es ser uno más, participar económicamente, del mercado laboral, de las relaciones sociales, de vecindad, de parentesco, de amistad. Poder participar políticamente. La participación es la que nos convierte en semejantes, nos hace sentir miembros y constructores del edificio que nos permite vivir a todos".

La fuerza centrífuga de la excusión va expulsando hacia los márgenes de la sociedad cada vez a más tipos de personas: migrantes en situación irregular, trabajadores y trabajadoras precarias, estudiantes sin experiencia laboral, familias monoparentales, etc. En esta dinámica podemos encontrar una oportunidad; es desde allí desde donde podemos empezar a fraguar el cambio. La desigualdad material no impide toda forma de revolución. Centro y márgenes, en definitiva, no se encuentran en el mundo físico, sino en nuestra mirada.

Hemos de lograr que nuestro trabajo como trabajadores y trabajadoras sociales ayude a transformar la sociedad en torno a valores como justicia social, humanismo y la participación, volver a poner en valor lo público y lograr que los discursos de odio no enturbien este proceso.

La inclusión comienza en nuestra mirada. Hemos de resignificar los márgenes, pasar de la marginalidad a la diversidad. De esa tensión entre centro y margen es de donde debe surgir la fuerza colectiva que desestabilice un centro que excluye, para transformar nuestra sociedad en un lugar que nos incluya a todos y todas.

Jonás Tristán Espinosa Quintanar Trabajador Social de la Asociación de acción social Libélula e ICEAS Miembro del OEISM 